\title{
Kärntens Mobilitätsvision 2035
}

\author{
R. Holub
}

Online publiziert am 14. Februar 2017

(c) Springer Verlag Wien 2017

Das Bundesland Kärnten hat im Sommer 2014 sowohl in der Landesregierung als auch im Landtag den Energiemasterplan einstimmig beschlossen. Dieser wurde mit Hilfe einer breiten Bürgerbeteiligung von über 2000 Personen erstellt. In diesem Masterplan ist der Ausstieg aus der fossilen und atomaren Energieversorgung des Landes Kärnten festgeschrieben. Im Bereich des Stroms und der Raumwärme sollen die Ziele bis 2025 erreicht werden, und im Bereich der Mobilität soll bis 2035 kein Benzin und Diesel mehr zum Einsatz kommen.

Obwohl der Bereich der Mobilität bereits im Energiemasterplan bearbeitet wurde, war es mir als Verkehrslandesrat sehr wichtig, gemeinsam mit der Bevölkerung auch einen eigenen Mobilitätsmasterplan für Kärnten zu erstellen. Dieser wurde 2016 vorgelegt und enthält viele Detaillösungsvorschläge bis 2035 im Bereich der Verkehrsplanung. Die Vision im Mobilitätsmasterplan sieht einen Modal Split von 20 \% Öffentlichen Verkehr, 40 \% Rad- und Fuß gängerverkehr und $40 \%$ Individualverkehr vor.

Aus der Kombination und Umsetzung der beiden Masterpläne ergibt sich für Kärnten die Mobilitätsvision 2035: Demnach sollen zunächst die öffentlichen Verkehrsmittel ausgebaut und elektrifi- ziert werden. Im Bereich der Bahn wird die 100-\%ige Elektrifizierung bis 2023 abgeschlossen sein. Bei den Bussen wäre Zeit für die sukzessive Umstellung bis 2035. Gleichzeitig sollen selbstfahrende und selbstladende Systeme eingeführt werden. Ein Bespiel für die Elektrifizierung der Fahrzeuge und den Umstieg auf öffentliche Verkehrsmittel ist die aktuelle Umstellung des landeseigenen Fuhrparks mit 270 Dieselfahrzeugen. Das mittelfristige Ziel dabei lautet: ein Drittel wird eingespart und mit öffentlichen Verkehrsmitteln bewältigt, ein Drittel wird auf Elektromobile umgestellt und ein Drittel bleibt zunächst mit Diesel betrieben. 2016 wurden bereits 25 Elektrofahrzeuge bestellt und 2017 sollen weitere 40 Elektroautos folgen.

Beim Individualverkehr werden Elektro-Carsharing-Systeme forciert. Die Ladeinfrastruktur wurde im öffentlichen Raum in den vergangenen Jahren bereits sehr gut ausgebaut. Der nächste Schritt zum Ausbau der Ladeinfrastruktur für Elektrofahrzeuge wird in Form von Förderungen und Vorschriften im Wohnhausbereich stark unterstützt.

Somit ist Kärnten am besten Wege, im Bereich der Mobilität das fossile Zeitalter zu verlassen und auf Elektromobilität umzustellen.

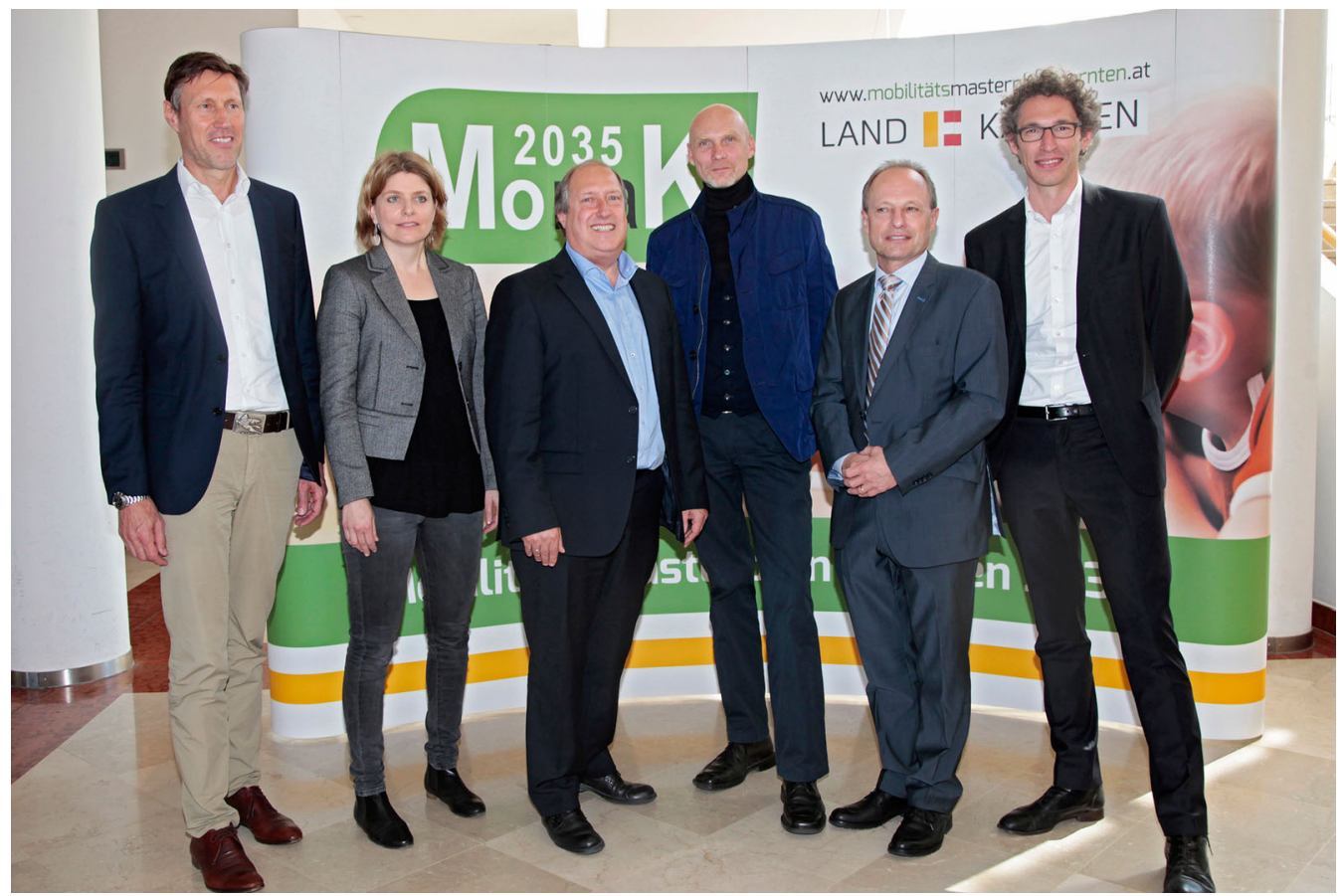

Büro LR Holub

Kurzfassung eines Vortrags bei der 54. Fachtagung der Österreichischen Gesellschaft für Energietechnik (OGE) im OVE, die am 24. und 25. November 2016 in Villach stattfand.

Holub, Rolf, Landesrat, Amt der Kärntner Landesregierung, Arnulfplatz 1, 9021 Klagenfurt am Wörthersee, Österreich (E-Mail: rolf.holub@ktn.gv.at) 